Autoexperimentación y bioética

\title{
GLASER, $\mathrm{H}$. \\ Medicina Dramática. Experimentos heroicos de los médicos. Luis de Caralt, Barcelona, 1962.
}

\begin{abstract}
Fernando Lolas Stepke ${ }^{1}$
El subtítulo de este libro indica su contenido. Se trata de recordar y comentar aquellos ejemplos de autoexperimentación conocidos, en los cuales personas, a menudo médicos, se sometieron voluntariamente a condiciones peligrosas.
\end{abstract}

Las motivaciones fueron varias. Probar una hipótesis, reconocimiento, auténtico deseo de obtener conocimientos, imposibilidad de contar con voluntarios para experimentar o, simplemente, curiosidad.

Por cierto, tanto en esta condición como en las investigaciones con sujetos humanos vale la pregunta de los riesgos y su justificación moral. En algún caso se podría presumir riesgosa inconsciencia o afán de autodestrucción, equivalente a un intento de suicidio. En cualquier caso, la autoexperimentación riesgosa requiere un análisis desde el punto de vista moral. Es obvio que a los ejemplos mencionados en este libro deben sumarse muchos otros, anónimos, de los que no quedó registro escrito. Por otra parte, considerando la literatura médica de hoy, con su clásico "paper" monótono, sería muy difícil que experiencias personales fueran admitidas como publicaciones científicas.

De los casos no se extraen principios generales como para hacer de esta experimentación un método. Algunos ejemplos muestran gran minuciosidad, como el de Santorio Santorio quien, durante años, registró sus alimentos y sus evacuaciones pesando su cuerpo. O los protocolos de los descubridores del ácido lisérgico, que escribieron detalladamente sobre sus experiencias. En otros casos se trató de actos arriesgados sin adecuada planificación, inspirados por el deseo de probar un punto. Un clásico es el de Max Pettenkofer, quien tragó un cultivo de bacilos del cólera para demostrar que el agente patógeno no siempre provoca enfermedad y que ésta es el resultado de un complejo juego de múltiples factores.

Algunos ejemplos son considerados heroicas intervenciones que ayudaron al progreso médico. Werner Forsmann, introduciéndose un catéter hasta el corazón, impresiona por lo deliberado del intento. Su técnica ingresaría al conjunto de procedimientos médicos. Los casos de Walter Reed y Carrión, inoculándose fiebre amarilla y bartonelosis, son recordados como heroicos. El primero se salvó, no así su colaborador Lezar, pero el segundo murió por la verruga peruana.

El caso de Hannes Lindemann es excepcional no solamente desde el punto de vista médico. Cruzar el océano en un bote y estar aislado durante varias semanas permite recoger valiosas indicaciones para vuelos espaciales, situaciones de aislamiento o naufragios. Demuestra no solamente audacia sino también resiliencia, habilidad y capacidad psicológica para afrontar la soledad. Aunque con diferencias, el caso de Lindbergh es semejante, aunque en éste predomina también el aspecto técnico de su avión.

John Hunter, un hombre ilustre en la medicina inglesa, intentando demostrar que la gonorrea y la sífilis son una misma enfermedad, se inoculó material de una persona que lamentablemente padecía de ambas enfermedades, las que contrajo. De modo que el experimento confirmó un error. Mucho tiempo después se probó la independencia de sífilis, gonorrea y chancro blando.

\footnotetext{
${ }^{1}$ Profesor Titular y director del Centro Interdisciplinario de Estudios en Bioética, Universidad de Chile. Investigador, Universidad Central de Chile. ORCID: https://orcid.org/0000-0002-9684-2725

Correspondencia: flolas@uchile.cl
} 
En el campo de la nutrición, la autoexperimentación ha sido frecuente, con resultados a veces graves. Purkinje, probando diversas dietas o ayunando. Otros investigadores, examinando los efectos de las carencias para determinar avitaminosis. En conjunto, tanto o más arriesgadas experiencias que las de quienes ingirieron drogas cuyos efectos no estaban completamente dilucidados.

Este libro es una colección de casos. Un anecdotario. Poco reflexiona el autor sobre motivaciones, consideraciones morales o importancia de esta fuente de informaciones para el "corpus" de la medicina. Aparte de decir que muchas de estas personas fueron mártires o héroes, queda al lector la tarea de reflexionar y saber que, en los hechos, casi toda la práctica médica es un ejercicio en toma de riesgos. Cuando un médico se acerca a un enfermo infectado no solamente se pone en riesgo personal. También su familia queda expuesta. La medicina en tiempos de pandemias y epidemias es de suyo riesgosa. No solamente para los médicos sino para todo el personal sanitario. De allí a tomar riesgos extraordinarios, adicionales a los propios de la profesión, hay un acto de voluntad especial que merece examen. ¿Debieran prohibirse tales actos? ¿Es siempre alguien dueño de su propio cuerpo y mente cuando, de resultas de tales actos, otros pudieran sufrir perjuicio?

En los tiempos que corren, debería retomarse esta veta autobiográfica de la tarea científica. Sin duda, los informes no siempre estarán acordes con la retórica del trabajo científico "de corriente principal", pero sin duda enriquecerían el acervo de los lectores. Quien más, quien menos, aparte de los principios generales del oficio, tiene con éste una relación personal. La autoexperimentación es ubicua y debiera ser norma su protocolozación por parte de observadores entrenados y acuciosos. 